\title{
Mediação e bibliotecas públicas: uma perspectiva dialética
}

\author{
Ana Amélia Lage Martins
}

Bibliotecária e Mestre em Ciência da Informação. Doutoranda em Ciência da Informação pela Escola de Ciência da Informação - ECI/UFMG.

http://dx.doi.org/10.1590/1981-5344/2298

O artigo apresenta e discute os diferentes empregos do conceito mediação, enfocando a Ciência da Informação e Biblioteconomia brasileiras, tendo em vista apontar uma perspectiva, com ênfase na dialética, para se pensar a mediação no âmbito das bibliotecas públicas.

Palavras-chave: Mediação. Bibliotecas públicas. Mediação da leitura. Mediação da informação.

\section{Mediation and library: a dialetical perspective}

The article aims at presenting and discussing the different uses of the term mediation emphasizing the Brazilian Information Science and Library,pointing out a dialectical perspective to think about mediation in the scope of public libraries.

Keywords: Mediation. Public libraries. Reading mediation. Information mediation.

Recebido em 11.12.2014 Aceito em 12.12.2014

\section{Introdução}

A presença do termo mediação na literatura da Ciência da Informação e Biblioteconomia brasileiras já se tornou, há algum tempo, bastante habitual.

Conjugado frequentemente aos vocábulos informação e leitura, designando as expressões "mediação da informação" e "mediação da leitura", a mediação foi incorporada na área por diferentes perspectivas teóricas e epistemológicas, sendo utilizada no âmbito dos estudos sociais 
da informação, do tratamento e recuperação de registros em sistemas, da gestão da informação e conhecimento em organizações, do desenvolvimento de linguagens classificatórias, dentre outros.

Uma forte evidência de que a mediação na Ciência da Informação brasileira é reconhecida como um termo de relevância no cerne do aparato conceitual e terminológico do campo pode ser encontrada na existência de um grupo de trabalho ${ }^{1}$ da Associação Nacional de Pesquisa e Pós-Graduação em Ciência da Informação- ANCIB- que traz em sua denominação o termo mediação. Trata-se do GT Mediação, Circulação e Apropriação da Informação, que tem sua gênese derivada do antigo grupo Informação e Sociedade/Ação Cultural, vigente por 10 anos como um fórum temático aglutinador de questões e olhares convergentes dentro do campo, relacionados à dimensão social, cultural, política e histórica do objeto informacional.

Outro indício revelador da presença marcante da mediação na área é a apresentação do termo na nomeação de grupos e linhas de pesquisas. Em uma busca orientada pela área de Ciência da Informação no Diretório dos Grupos de Pesquisa do Brasil ${ }^{2}$, base de dados do CNPq veremos a existência de linhas de pesquisa denominadas "Gestão, Mediação, Acesso e Uso da Informação", "Mediação da Informação", "Mediação da leitura", bem como de grupos denominados "Núcleos de estudos em informação e mediações comunicacionais contemporâneas"; "Fluxos e mediações sóciotécnicas da informação"; "Grupo de Estudos e Pesquisa em Mediação e Comunicação da Informação".

Para o CNPq uma linha de pesquisa aglutina estudos científicos que se "fundamentam em tradição investigativa, de onde se originam projetos cujos resultados guardam afinidades entre si" (CONSELHO NACIONAL DE PESQUISA, 2013). O grupo de pesquisa, por seu turno, congrega pesquisadores, estudantes e pessoal de apoio técnico, organizados em torno da execução das linhas de pesquisa e que se agrupam hierarquicamente a partir da experiência e da competência técnicoadministrativa.

A existência de grupos e linhas de pesquisa que alocam a mediação figurando de modo expressivo- ao exibir-se em sua própria nomeaçãofornece-nos sinais tanto de que ela se inscreve, em dada medida, em uma "tradição investigativa", denotada pela linha, quanto de que ela agrega pesquisadores e estudantes que tem como convergência a reflexão sobre tal tema.

Além disso, já se tornou bastante corriqueiro para os profissionais que trabalham com bibliotecas públicas, escolares, universitárias ou comunitárias utilizar expressões que incorporam o termo mediação designando práticas, projetos e processos dos mais distintos, o que inclui

\footnotetext{
1 De acordo com o Conselho Nacional de Pesquisa, os grupos de trabalho se destinam a abrigar questões, objetos e temáticas que estabelecem afinidades entre si.

${ }^{2}$ O Diretório dos grupos de pesquisa do Brasil começou a ser elaborado a partir de 1992 com o objetivo de reunir informações atinentes às pesquisas desenvolvidas no país. Por meio de uma consulta a esta base é possível encontrar descrições sobre grupos, linhas de pesquisa, temáticas privilegiadas, recursos humanos envolvidos, bem como interações entre grupos de pesquisas e o setor produtivo. Estas informações são atualizadas diariamente e, por meio dos censos realizados bi-anualmente, é possível também visualizar quantitativamente o perfil da pesquisa no Brasil.
} 
até denominação de uma "função" que vem se tornando emergente: o mediador. Há, na esfera do mercado, da política pública e ainda por parte da sociedade civil, inúmeros cursos e ações de formação de "mediadores culturais" e "mediadores de leitura", bem como projetos de "mediação da leitura" que seriam executados por estes agentes, capacitados para realizar a "mediação" nas bibliotecas e outros equipamentos de cultura. Nestes discursos, esta mediação contempla ações de variadas naturezas que incluem desde o tradicional serviço de referência, o acompanhamento dos leitores, a oferta de livros, o desenvolvimento de atividades que contemplam um leque variado de linguagens, tais como oficinas de produção artística, rodas de leitura, cinema, a orientação de visitas em bibliotecas, centros culturais e museus até a atuação no âmbito da formulação das políticas públicas.

Diante deste cenário caleidoscópio no qual se insere a mediação no campo, este texto busca levantar algumas questões para os estudos que lançam mão do termo: afinal, o que é a mediação? Quais as suas particularidades e a sua natureza? Como ela é tratada pela Ciência da Informação brasileira? O que este conceito polissêmico traz ou pode trazer para a construção do conhecimento no campo e para o pensamento conceitual, político e metodológico acerca das bibliotecas públicas?

Mediação: termo plural

Etimologicamente, a palavra mediação vem do latim mediatione que designa intervenção humana entre duas partes ${ }^{3}$, a ação de dividir em dois ou estar no meio, indicando ideias de interveniência, relação, conjugação, religação, ponte ou elo estabelecido nas relações humanas, por meio de um elemento mediador.

Williams (1985) aponta que na língua inglesa o mais antigo uso do termo que se tem conhecimento fora feito por Chaucer na obra TheMan ofLaw's Tale em 1386, referindo-se ao modo de interceptação entre dois adversários com vistas à conciliação entre ambos.

No pensamento clássico desempenha função importante o chamado "termo médio", ou "meio-termo", cujo papel de mediador no raciocínio permite que se torne possível uma conclusão a partir de determinada premissa.

O conceito de mediação tem como marco também a vertente filosófica idealista alemã de origem cristã que, ligada à herança teológica, assinalava a mediação do Cristo entre Deus e o mundo e a mediação dos santos entre Deus e os pecadores.

Lalande (1993) lembra que embora o significado mais recorrente do termo mediação ligue-se à ideia do intermediário, o emprego filosófico do conceito não se limitou a esse sentido, podendo não se aplicar ao próprio elemento intermediador, mas àquele que se restringe ao primeiro ou dele deriva por intermédio do segundo (LALANDE, 1993) indicando a noção de processo.

${ }^{3}$ RUSS, 1994, p. 180. 
Preconiza-se também que o conceito fora utilizado de forma implícita ou explícita por vários filósofos da Antiguidade Clássica, quando estes se viram ante a necessidade de encontrar um modo de relacionar dois elementos diferentes. Assim, a mediação foi entendida como a atividade própria de um agente mediador que era, ao mesmo tempo, uma realidade intermediária (PUGLIESI; BINI, 1977).

No pensamento clássico desempenha função importante o chamado "termo médio", ou "meio-termo", cujo papel de mediador no raciocínio permite que se torne possível uma conclusão a partir de determinada premissa.

Em geral, a mediação em um processo discursivo é o que torna possível tal raciocínio: de fato, em um processo discursivo, tanto dedutivo como indutivo, são necessários termos ou juízos que 'medeiam' entre o ponto de partida e a conclusão (PUGLIESI; BINI, 1997, p. 252).

Em Ética a Nicômaco, Aristóteles apresenta a virtude como uma mediedade (mesotês) entre o excesso e a falta, sendo o meio termo "o que dista igualmente de cada um dos extremos, que justamente é um único e mesmo para todas; por meio relativo a nós, o que não excede nem falta" (ARISTÓTELES, 2002, p. 15).

O conceito de mediedade, formulado a partir da consideração do meio-termo como virtude, é essencial para o entendimento da ética aristotélica. Em sua definição da virtude, o filósofo estabelece três tipos de fenômenos formulados na alma: as paixões, as capacidades e as disposições.

Por paixão compreendem-se as inclinações acompanhadas pelo prazer e pela dor tais como a cólera, o temor, o apetite e a audácia. As capacidades encerram a possibilidade que os homens têm de vivenciar a paixão. As disposições, por sua vez, referem-se à conduta boa ou má diante das paixões.

As paixões e as capacidades não são consideradas pelo filósofo como gêneros da virtude, o que faz com que esta seja entendida como disposição, a qual será responsável por orientar o homem a agir com mediedade diante das paixões.

Desse modo, um homem se torna dotado de virtude na medida em que alcança o meio termo entre excesso e falta. A virtude encerra, então, "uma disposição de agir de maneira deliberada, consistindo em uma mediedade relativa a nós, disposição determinada pela razão, isto é, como determinaria o homem prudente" (ARISTÓTELES, 2002, p. 12). ${ }^{4}$

${ }^{4} \mathrm{O}$ conceito de meio termo, central para o entendimento da doutrina aristotélica sobre a virtude moral, é distinguido entre o "meio termo da coisa" e o "meio termo relativo a nós". O primeiro compreende uma proporcionalidade aritmética: "se dez é muito e dois é pouco, toma-se o seis como meio termo da coisa" (Aristóteles, 2002, p. 23). O "meio termo relativo a nós" compreende algo que se situa entre o excesso e a escassez, conforme demonstra o filósofo: 
Será, pois, pela dialética que a mediação se desenvolverá como uma categoria para se pensar o real. A partir da filosofia de Hegel e, posteriormente, de Marx, a mediação estará relacionada à articulação entre as partes de uma totalidade complexa, sendo à ela atribuída a responsabilidade pela passagem entre o imediato e o mediato. Está, portanto, vinculada à ideia de processo e movimento que fundam a dialética.

\section{Uma categoria dialética}

A lógica dialética tem sua gênese nas ideias de Heráclito, pensador que acreditava no movimento, na mudança, na transitoriedade e na contrariedade. Sócrates também a utilizou no curso do desenvolvimento de sua filosofia a partir da consideração dos três momentos que constituem a elaboração do conhecimento: hipótese, designando a definição prévia e provisória do que se almeja conhecer; a ironia, interrogatório que conduz o interlocutor ao reconhecimento da ignorância do que intentava saber; e a maiêutica, arte de dar à luz as ideias adormecidas no espírito do interlocutor.

Para Platão, a dialética é o processo por meio do qual a alma ascende, por níveis, das aparências sensíveis às realidades inteligíveis. Por meio do verbo dialeghestai, cujo sentido etimológico remete a ideia de "diálogo" e "dialogar", o filósofo assinalou a passagem do logos na comunicação entre dois interlocutores. A partir desta perspectiva, a dialética é entendida como "um instrumento de busca da verdade, uma pedagogia científica do diálogo graças ao qual o aprendiz de filósofo utiliza sistematicamente o discurso para chegar à percepção das essências, isto é, à ordem da verdade" (BRAGA, 2004, p. 2).

Em sua explanação sobre a dialética, Konder (1981) assinala que "a experiência nos ensina que em todos os objetos com os quais lidamos existe uma dimensão imediata (que nós percebemos imediatamente) e existe uma dimensão mediata (que a gente vai descobrindo, construindo ou reconstruindo aos poucos)" (KONDER, 1981, p. 48).

A dupla dimensão da experiência (imediata e mediata) é, para Hegel, fundamental para a compreensão do movimento dialético que constitui a realidade, esta vista pelo ponto de vista de sua totalidade ${ }^{5}$.

se a alguém comer dez minas de peso é muito e duas é pouco, não é verdade que o treinador prescreverá seis minas, pois isto talvez seja pouco ou muito para quem as receberá: para Mílon será pouco, para o principiante nos exercícios será muito (ARISTÓTELES, 2002, p. 36).

O "meio termo relativo a nós" deve ser compreendido como um princípio relacional, tendo em vista que o "nós" significa aquilo que é relativo ao agente e às circunstâncias nas quais o agente está inserido. Assim, sua procura torna-se complexa e particular (MENEZES; HOBUSS, 2009)

${ }^{5} \mathrm{~A}$ totalidade é um conceito central na filosofia hegeliana e no método dialético marxista. Exprime um todo dinâmico, em constante desenvolvimento, em unidade de contrários, cujo conhecimento é um processo de 
De acordo com a filosofia hegeliana, a mediação seria um momento da dialética em que o ser retornaria a si através da negação.

Enquanto Espírito o homem não é um imediato, mas essencialmente um ser que retorna a si. Este movimento de mediação é um momento essencial do Espírito. Sua atividade consiste em sair da imediatez, em negá-la e retornar assim, a si (HEGEL, 2008, p. 78).

Almeida, Arnoni e Oliveira (2006) apontam que:

como categoria filosófica, a mediação atinge seu pleno desenvolvimento em Hegel. Daí o seu caráter dialético, que a impede de ser entendida fora dessa perspectiva de análise, bem como de ser considerada como produto: ela é processo, pois funda-se na tensão e no movimento (ALMEIDA; ARNONI; OLIVEIRA, 2006, p. 2).

Guarady destaca no método hegeliano a posição da mediação e a relação entre o mediato e o imediato.

Todo conhecimento real deve passar por três momentos: o do imediato ou do universal abstrato, depois o de sua negação, que é reflexão, mediação, e o da totalidade concreta, do universal concreto, isto é, do resultado que conserva e contém nele o momento da negação, da reflexão, da mediação. Dizer que o método do conhecimento é dialético é dizer que não poderia existir conhecimento imediato. É negar somente a possibilidade de possuir a verdade por uma intuição sensível, direta, mas também de alcançar a verdade por um conceito isolado (GUARADY, 1983, p. 28).

Assim, o conhecimento mediato compreende um momento ulterior, de negação e reflexão, acerca do conhecimento imediato, sendo responsável por evidenciar as contradições ${ }^{6}$ que atravessam a realidade.

De acordo com Hegel, a relação entre o imediato (unmittelbar) e a mediação (vermittlung) provoca uma oposição lógica que deve ser conciliada. O movimento, por ser intermitente, não se configura por limites, princípio ou término. Contudo, isso não o caracteriza como desarranjado, pois a ordem se instaura através da negação mútua estabelecida entre os elementos da relação.

Essa negação recíproca não consente que a mediação, pela perspectiva dialética, abarque "ideias que tenham por princípio a 
igualdade, a homogeneidade e o equilíbrio" (ALMEIDA; ARNONI; OLIVEIRA, 2006, p. 2).

De acordo com Almeida (2004), o mediato não supera o imediato, quem o faz é a mediação, assim, a força inerente à superação não se manifesta nos polos da relação, imediato e mediato, ela é uma propriedade da mediação.

A passagem de uma coisa a outra ou de um estado a outro por meio da superação não suprime a coisa ou o estado superados, ao contrário, integra-os àqueles que os superaram. Eles não são suprimidos porque também contribuem no processo de superação. A mediação na qual se dá a superação, não é unilateral nem excludente, busca a totalidade e, assim, combate a unilateralidade da parte sem excluí-la do todo e, ao mesmo tempo, sem diluí-la nele (ALMEIDA, 2004, p. 3).

Ao criticar a concepção idealista da dialética hegeliana e incorporar o postulado materialista de Feuerbach, Marx faz da dialética o método do materialismo histórico. O filósofo realiza a inversão dos termos da dialética, conferindo primazia aos conteúdos materiais ou históricos. Isto é, enquanto que para Hegel o pensamento é responsável por criar a realidade, para Marx o dado primeiro é o mundo material, sendo que a contradição surge entre homens reais, em condições históricas e sociais reais.

Sua visão, que busca superar a dicotomia entre sujeito e objeto, fundamenta-se, pois, na consideração de que uma realidade, inscrita em um dado período histórico, se comporta como um todo articulado, perpassado por contradições específicas em que as condições materiais da vida são centrais para seu engendramento e, portanto, para seu entendimento.

Assim, o mundo material é dialético, isto é, está em constante movimento, e historicamente, as mudanças ocorrem em função das contradições surgidas a partir dos antagonismos das classes no processo da produção social.

Além de apreender a mediação como articulações externas e internas entre as polaridades, uma formulação elaborada "pela razão de forma lógica a fim de possibilitar a apreensão do movimento do real" (BRAGA, 2004, p. 4), a dialética marxista também a entende como uma categoria ontológica, ou seja, na composição do ser social.

Marx apontou o trabalho como o mediador entre homem e natureza, identificando na atividade produtiva do "ser natural automediado" a condição vital da autoconstituição humana.

Para ele é a partir da mediação pela atividade sensível, da atuação transformadora no mundo material, que o homem se exterioriza e produz o seu mundo. Assim, objetividade e exterioridade são mostradas pela relação entre homem e natureza (BRITO, 2009). Cumpre ressaltar que Marx concebe a natureza como: a) um todo coerente em que os 
fenômenos se condicionam reciprocamente; b) um estado de mudança e de movimento; c) o lugar onde o processo de crescimento das mudanças quantitativas gera, por acumulação e por saltos, mutações de ordem qualitativa; d) como a sede das contradições internas, tendo um lado positivo e o outro negativo, um passado e um futuro, o que provoca a luta das tendências contrárias, gerando o progresso (JAPIASSÚ; MARCONDES, 1996).

O trabalho compreende o momento em que o "homem natural" é transposto para o "homem social", sem, contudo, recusar seu fulcro natural. Marx não compreende o trabalho limitando-o como atividade puramente natural, física e biológica. De acordo com o filósofo alemão, ao alterar a natureza por meio do trabalho, o homem produz subjetividade e objetividade próprias a ele, dimensões determinadas também no processo de trabalho.

Como categoria destinada a pensar a realidade, a "mediação" ganhou inúmeros contornos conceituais a partir dos sistemas referenciais aos quais fora articulada. Isto porque o movimento de "migração de conceitos" implica na intervenção sobre um complexo de fatos e de sistemas relacionais e na atribuição de novos sentidos a termos que têm sua gênese ligada a contextos e campos específicos, o que faz com que o conceito tomado de empréstimo signifique, muitas vezes, fenômenos diversos (MARTINS; REIS, 2014). É o que se pode vislumbrar nos estudos da Psicologia, da Antropologia, da Comunicação e de outras disciplinas das ciências sociais e humanas que empregaram tal conceito como mote para o entendimento do real e as relações sociais operadas nele ${ }^{7}$.

$\mathrm{Na}$ Ciência da Informação brasileira, para onde o conceito fora também levado e onde logrou considerável repercussão, a mediação

\footnotetext{
${ }^{7}$ Em linhas gerais tem-se que a psicologia trata a mediação como elemento-chave da relação do homem com o mundo e dos indivíduos entre si. Esta perspectiva tem como expoente os trabalhos de Vygotsky, que concebe a mediação como fundamental para a compreensão do desenvolvimento humano, pautado nas relações mediadas entre os sujeitos e a realidade. Do ponto de vista jurídico, a mediação aponta sempre para a solução de conflitos entre duas partes em disputa. Diferente da negociação, na qual o interveniente representa o interesse de uma das partes, a mediação jurídica pressupõe a existência de um intermediário neutro e imparcial para a equação da controvérsia em pauta. A Antropologia estuda a mediação e, especificamente os mediadores, como modo de perceber a natureza e os domínios das interações entre categorias sociais e níveis culturais distintos colocando em destaque a interação social, a natureza simbólica da cultura e o trânsito de distintos códigos culturais entre grupos sociais. Por esta perspectiva a mediação é entendida também pelo prisma da aproximação de sujeitos a produtos e artefatos culturais, como obras de arte, livros, exposições e espetáculos, a partir do conceito de mediação cultural. No campo da comunicação quem primeiro referiu-se às mediações foi Manuel Martin-Serrano que, em 1977, propôs uma "teoria da mediação social" no âmbito da comunicação, em contrapartida ao funcionalismo e utilitarismo de origem norte-americana que dominava o campo de estudos da área. De um ponto de vista racionalista e sistêmico, Martin Serrano indicará que as mediações vão além dos meios de comunicação, sendo responsáveis por produzirem modelos de ajuste que operam com recursos, práticas e visam resolver as dissonâncias geradas pelo conflito entre inovações e normas culturais. Para ele, em uma sociedade que se define em crise, o controle social é exercido como um ajuste técnico, cuja função é produzir instituições mediadoras e objetos de para restabelecer o equilíbrio no estado de deficiência permanente. As instituições mediadoras, entre elas os meios de comunicação, propagam um modelo lógico para interpretar e integrar a contradição, colocando em ordem a nível formal a desordem existente no nível real, de maneira que a própria contradição sirva a reprodução social e a totalidade da ordem social não seja questionada (MARTIN SERRANO, 1978 apud GÁMEZ TORRES, 2007). Na América Latina, Martin-Barbero apresenta uma perspectiva teórico-metodológica que incide luz sobre os modos pelos quais as pessoas se relacionam com os meios e processos comunicacionais. Sua visão realoca os problemas de comunicação em outro campo: o dos processos socioculturais, a partir do qual o autor proporá o estudo dos fenômenos de comunicação através das mediações. O deslocamento conceitual que transita "dos meios às mediações", baseia-se na concepção de que, nos espaços da comunicação há um denso amálgama de crenças, valores, aspirações, temores e costumes, que formulados cotidianamente, se conformam em cultura.
} 
ganhou diferentes significados, tendo em vista que se articulou à perspectivas epistemologicamente distintas no campo.

\section{Mediação na Ciência da Informação brasileira: um panorama}

De acordo com a pesquisa realizada por Martins (2010), o termo mediação na Ciência da Informação brasileira tem sido empregado historicamente para designar práticas, operações e processos que envolvem o fluxo, a transferência e a apropriação da informação, bem como a elaboração de conhecimento e a produção de sentidos pelos sujeitos, podendo estar apoiada no agente mediador especializado, o bibliotecário ou "profissional da informação", e nos dispositivos tecnológicos (MARTINS, 2010) ${ }^{8}$.

Analisando a inserção e a apropriação deste termo pela Ciência da Informação e Biblioteconomia brasileiras, o trabalho revelou que a mediação emerge de modo seminal na literatura destes campos com um artigo do bibliotecário francês Victor Flusser, datado de 1980. "Uma biblioteca verdadeiramente pública", publicado na Revista da Escola de Biblioteconomia da UFMG, discute as dimensões consideradas pelo autor como fundamentais em uma biblioteca que exerça efetivamente sua condição de "pública", à qual o autor designa como "biblioteca-ação cultural".

Para ele, as principais atribuições de uma biblioteca pública consistem na "procura do contato com o não-público e a síntese dialética entre criação e mediação cultural" (FLUSSER, 1980, p. 131).

O autor parte da perspectiva de que com o desenvolvimento do espírito individualista burguês, as relações entre homem e cultura, bem como entre criador e público, são alteradas de maneira significativa, pois: "se na Idade Média a criação artística tinha uma utilidade social globalmente aceita, era um bem simbólico, pertencia ao domínio público, com a Renascença, ela tende a ser uma fruição individual e um bem econômico" (FLUSSER, 1980, p. 131). Esta modificação é o início de um processo de distanciamento- que foi corroborado por outros fatores sociais e econômicos- entre alguns grupos sociais e a cultura, movimento que vai se acelerando até culminar em uma ruptura, responsável pelo estabelecimento da dicotomia que colocou: "de um lado um público efetivo ou potencial do fenômeno cultural, e do outro um público deixado de lado" (FLUSSER, 1980, p. 132).

De acordo com Flusser (1980), é para o "não público", aquele correspondente à maioria da população, para o qual uma "biblioteca verdadeiramente pública" deve, prioritariamente, voltar o olhar. Segundo ele:

\footnotetext{
8 "Mediação: reflexões no campo da Ciência da Informação brasileira", realizada por Martins (2010). O estudo foi conduzido a partir da análise de um corpus formado por material textual proveniente de encontros científicos e artigos de periódicos especializados em Ciência da Informação, composto por 164 unidades amostrais baseadas nos critérios de homogeneidade, representatividade e relevância. A partir deste universo, o trabalho buscou traçar uma cartografia do termo no campo, identificando suas origens e o tratamento teórico e metodológico dado a ele.
} 
para que uma biblioteca pública possa vir a ser plenamente pública é necessário que ela se volte para o não público. [...] É necessário romper com o isolamento do não público, isolamento não circunstancial, mas essencial. A cultura na sua pluralidade de expressão não lhe diz respeito. Não se estabelece entre o não público e a cultura um diálogo. [...] A cultura do nãopúblico é a cultura do silêncio (FLUSSER, 1980, p. 133).

Embora o significado de mediação não seja formalmente apontado no texto, o autor indica que mediar compreenderia uma ação que tem em vista a síntese entre o contexto cultural e os acervos, considerando o processo social que culmina na distância entre o público e a biblioteca. A animação, neste sentido, é uma ação política que tem em vista a superação, de forma crítica, deste distanciamento.

No âmbito dos Encontros Nacionais de Pesquisa e Pós Graduação em Ciência da Informação e Biblioteconomia, a mediação aparece em primeiro momento vinculada aos estudos sociais da informação tratados pelo grupo de trabalho "Informação e Sociedade/Ação Cultural" que passa a se chamar, em 2005, "Mediação, circulação e uso da Informação" e posteriormente, em 2009, "Mediação, circulação e apropriação da informação".

No trabalho de Ribeiro e Marteleto (1997) denominado "Conhecimento e novas práticas informacionais nas ações políticopedagógicas de organizações não governamentais (ONG's)" discutem-se as práticas formuladas no âmbito do conhecimento, da informação e da comunicação que, a partir de 1980, começam a pautar as atividades dos movimentos sociais e dos núcleos das ações coletivas como importantes estratégias de ação.

A abordagem à mediação, termo que não é teoricamente tratado, referencia o trabalho das ONGs, consideradas pelas autoras instâncias mediadoras dos movimentos sociais e da sociedade civil organizada. Neste trabalho, informação, comunicação e mediação se articulam na arena pública, fundamentando a ação política.

O mapeamento do termo mediação no campo demonstrou que se a exibição do conceito no grupo de trabalho "Informação e Sociedade/Ação Cultural" é tímida durante os cinco primeiros encontros em que o GT esteve atuante, ela se intensificará de modo significativo a partir da alteração do nome do grupo de trabalho, em 2005. Ao ser inserido na expressão que denomina este escopo de trabalho, o vocábulo mediação começará a circular no campo não apenas com mais frequência, como também com sentida naturalidade (MARTINS, 2010).

Embora não haja, na maioria das vezes, uma definição explícita do entendimento que se faz da mediação e, tampouco, consenso sobre os seus significados, o conceito passa aser vislumbrado principalmente a partir das seguintes perspectivas ${ }^{9}$.

\footnotetext{
${ }^{9}$ Cumpre ressaltar que tais perspectivas foram elaboradas a partir do aglutinamento de núcleos de abordagens à mediação, já que o termo, na maioria das vezes, não aparece formalmente conceituado.
} 
1) Cognitiva: enfoca a construção de conhecimento a partir da informação e o papel pedagógico das bibliotecas neste processo, utilizando-se referenciais advindos das Ciências Cognitivas. Destaca-se, nesta vertente, a apropriação da Experiência da Aprendizagem Mediada, modelo proposto por Reuven Feurstein.

2)Uso e apropriação das tecnologias de informação e comunicação: parte do entendimento tanto dos aparatos e dispositivos técnicos como mediadores da relação social e da apreensão do real, quanto sublinha os "modos de uso" engendrados por meio deles.

3)Significação e produção de sentidos: considera a combinação entre diferentes arranjos do conhecimento -como o empírico e o científico- e a utilização das tecnologias de informação e comunicação nos processos sociais de produção, circulação e apropriação da informação.

4)Transferencial: tem como horizonte a armazenagem e o acesso aos registros de informação, sendo a "mediação da informação", responsável por promover o acesso aos conteúdos informacionais.

No âmbito da Biblioteconomia, a compreensão mais sedimentada de mediação é a de elo e ponte estabelecidos por meio de um elemento terceiro, com vistas ao acesso à leitura e à informação. O emprego desta perspectiva, na maioria das vezes, converge-se à noção arraigada no senso comum que concebe a mediação como a ação de intermediação, destinada a promover o encontro entre dois elementos desconectados.

A noção de mediação como intermédio está ligada a um modo positivista de ver a realidade, uma visão que afasta as categorias em partes tidas por preexistentes e independentes entre si e que, por isso mesmo, "necessitam de outras categorias, externas a cada uma delas, para cumprir o papel de intermediárias e garantir as ligações que as tornam interdependentes" (WILLIAMS, 1985, p. 102).

Neste cenário, o bibliotecário passaria a assumir uma função de "mediador".

\section{0 bibliotecário mediador}

O bibliotecário (ou profissional da informação) emerge na literatura como o agente responsável e capacitado (ou com potencial para tal) para - exercício da mediação a partir da década de 1990. Como agente intermediário, sua função é tecer a trama entre os registros de informação e os usuários, ação cuja consequência é, na maioria das vezes, a satisfação de determinada "demanda informacional" (MARTINS, 2010).

Ratificando-nos esta tendência Almeida (2008) lembra que: 
se generalizou no campo de estudos da informação, a ideia de que um "profissional da informação" (independentemente dele eventualmente preferir ser chamado de bibliotecário, arquivista, museólogo ou outra definição profissional) cumpriria, na prática do trabalho, uma função de "mediador"(ALMEIDA, 2008; p. 3).

Como pano de fundo desta perspectiva há a consideração de que a mediação promovida por um agente implica na produção de um efeito da ação, em maior ou menor medida, sobre o destinatário: ele vai elevar-se, instruir-se, transpor, sendo que a ação do mediador encerra algum impacto sobre o ambiente (constantemente o ambiente social) onde ela se insere (DAVALLON, 2007).

Na literatura do campo nota-se que o bibliotecário converte-se em mediador na medida em que o cenário informacional torna-se mais complexo a partir da produção e utilização em larga escala das tecnologias de informação, que multiplicaram exponencialmente a geração de conteúdos informacionais, alterando as formas de relação do usuário com a informação e os modos de organização da mesma.

Esta tendência pode ser percebida em diferentes trabalhos, como no de Alves e Faqueti (2002) que defendem:

A adoção de um paradigma centrado no usuário, cujo foco é o usuário e não o sistema de informação, como no paradigma tradicional, pressupõe um novo papel, vislumbrado para o bibliotecário na era das novas tecnologias da informação. Este novo papel deverá ser respaldado por um modelo de mediação no qual o bibliotecário assume uma postura pró-ativa, cria situações que estimulem o gerenciamento da busca e de uso de informação a qual deverá gerar um novo conhecimento. Sem perder de vista que, o sujeito é quem gerencia e constrói o seu conhecimento quando reflete sobre o que conhece e o que deve conhecer. Razão pela qual os sistemas de informação devem promover a autonomia dos usuários criando situações que estimulem as estruturas cognitivas e afetivas desses usuários (ALVES; FAQUETI, 2002, p. 2).

Por esta perspectiva, que incorpora muitas vezes um discurso econômico e administrativo, a tecnologia é enfatizada amiúde: a) pela expectativa do porvir, do advento, de uma aproximação incessante; b) pela visão de que esta chegada provoca impactos e transformações em diferentes esferas da vida, o que exige adaptações e rearranjos, c) pela perspectiva de que a penetração tecnológica - definidora da "Sociedade da Informação" - é irreversível ou inevitável. É forte nestas concepções a delimitação temporal de um período no qual a tecnologia parece tornar-se um imperativo: trata-se de uma "era" que se aproxima apressadamente e 
que transforma de muitas maneiras a realidade social e para à qual todos, especialmente os bibliotecários, devem se adaptar (MARTINS, 2010).

Por meio destas abordagens, a mediação é parcamente problematizada e conceituada, empregada, também, a partir do conceito "mediação da informação", cujo principal traço é a função utilitária e operacional tanto da informação quanto da mediação. Nestes enfoques, informação e mediação são olhadas de um ponto de vista funcionalista e resolutivo, orientadas para a resolução de problemas, o que indica uma tendência em "dar respostas", privilegiando a resolução prática e operacional de questões ${ }^{10}$.

Ao lançaram mão do conceito "mediação da informação" ou "mediação da leitura", muitos estudos tomam como ponto de partida uma noção radicada no senso comum, compreendendo a mediação como ponte ou intermediação, sem que sejam problematizados os elementos e processos históricos que acabam por determinar a separação entre os elementos possivelmente mediados.

Sabe-se que a utilização, no campo científico, de visões arraigadas no senso comum torna problemático o encaminhamento da ruptura epistemológica, tão necessária à produção do conhecimento, já que a formulação de bases conceituais exige uma ruptura com as representações comuns da sociedade e com as explicações mais espontâneas acerca da realidade (BOURDIEU; CHAMBOREDON; PASSERON, 1999).

Neste sentido, questionar o senso comum, recuperar os elos conceituais, a natureza filosófica do termo, bem como entender seus modos de inserção no campo torna-se um exercício importante para a reflexão acerca da exequibilidade do conceito mediação no campo.

Por meio deste exercício é que se vislumbra um possível horizonte para se pensar a mediação no âmbito das bibliotecas públicas.

\section{Mediação e bibliotecas públicas: a construção de projetos contra-hegemônicos}

Ao vermos a mediação situada inicialmente no terreno da investigação acerca dos movimentos sociais, o qual contará, a partir da década de 70, com um expressivo aporte do marxismo de Gramsci, endossamos a pressuposição de Almeida (2007), autor que correlaciona o surgimento da mediação no campo da Ciência da Informação à incorporação e discussão de referenciais gramscianos.

Para o autor uma reflexão sobre a mediação no campo da Ciência da Informação e Biblioteconomia deve considerar como guia as concepções de Gramsci sobre hegemonia e cultura, pelo fato também de ambas terem sido abrigadas pelos Estudos Culturais ingleses, os quais foram amplamente recebidos no contexto dos estudos da comunicação e da

\footnotetext{
${ }^{10}$ Não se questiona aqui a relevância da dimensão resolutiva do campo que se firma tendo como sustentáculo a prática e o exercício da organização, sistematização e disponibilização de acervos de informação. Salienta-se, particularmente, que a apropriação de conceitos como modo de solucionar problemas de ordem prática pode ocasionar certo esvaziamento da discussão epistemológica e teórica que orienta a prática científica.
} 
cultura popular na América Latina e no Brasil, a partir de onde se fertiliza a ideia de mediação nas Ciências da Comunicação.

Uma das principais contribuições de Gramsci no âmbito da teoria marxista é, segundo ele é:

repensar as relações entre uma estrutura determinante (modo de produção) e uma superestrutura determinada (instituições jurídicas e políticas, formas de consciência, práticas políticas e culturais). A análise cultural, nessa chave, buscava revelar os mecanismos de falseamento, ilusão, não-consciência, mostrando como a superestrutura não era meramente o reflexo, mas a mediação das relações de produção (ALMEIDA, 2007, p. 4, grifo meu).

Em Gramsci, a ideia de hegemonia ultrapassa a dimensão do político abarcando também o cultural, o ideológico e o moral. Ela refere-se às formas de dominação que se estabelecem a partir da articulação do consenso de uma classe sobre outra, em que determinados blocos de poder organizam conhecimentos, sensos e sentidos de modo que estes pareçam inevitáveis e universais, fazendo com que a classe dominada conceba como "naturais" os interesses da classe dominante.

Segundo o pensador italiano, a hegemonia engendra-se por meio de disputas que excedem o escopo estrutural, econômico e político, abarcando a dimensão ética e cultural,

a expressão de saberes, práticas, modos de representação e modelos de autoridade que querem legitimar-se e universalizar-se. Portanto, a hegemonia não deve ser entendida nos limites de uma coerção pura e simples, pois inclui a direção cultural e o consentimento social a um universo de convicções, normas morais e regras de conduta, assim como a destruição e a superação de outras crenças e sentimentos diante da vida e do mundo (GRAMSCI, 2007, p. 65).

A articulação hegemônica é, portanto, um jogo dinâmico capaz de naturalizar o que historicamente representa uma ideologia de classe, convertendo-a em uma forma de senso comum. Sua conformação histórica está vinculada às forças sociais que a exercem e à luta pelo poder entre os grupos sociais no âmbito da sociedade.

De acordo com Gramsci:

O exercício "normal" da hegemonia, no terreno tornado clássico do regime parlamentar, caracteriza-se pela combinação da força e do consenso, que se equilibram de modo variado, sem que a força suplante em muito o consenso, mas, ao contrário, tentando fazer com que a força pareça apoiada no consenso da maioria (GRAMSCI, 2007, p. 95) 
Contudo, a hegemonia, como processo histórico, não é total e absoluta. A partir das contradições de natureza antagonista que se exprimem no conflito de interesses decorrentes do modo de produção e as relações entre os atores do Estado e sociedade civil insurgem articulações de resistência à subordinação total, as chamadas "contra-hegemonias" que questionam a ordem vigente, de modo a alterá-la.

Em sua filosofia, Gramsci também investiga a fundo "a estreita ligação entre intelectuais, política e classe social, mostrando que a filosofia, tal como a educação, deve tornar-se 'práxis política' para continuar a ser filosofia e educação" (GRAMSCI, 1975, p. 1066; apud SEMERARO, 1999, p. 5).

O intelectual na acepção gramsciana é um indivíduo que desempenha uma função organizadora no corpo social, elaborada por uma classe em seu desenvolvimento histórico. Este sujeito é entendido como aquele que atua em conjunto com uma classe, desempenhando um papel de vetor da consciência da mesma, de agregador da vontade coletiva e vetor da transformação social.

A organicidade destes intelectuais está relacionada, sobretudo, à sua extensa vinculação à cultura, à história e à política das classes subalternas que se organizam para construir uma nova civilização (SEMERARO, 1999). A definição do intelectual orgânico, categorizada por Gramsci em urbano, industrial, rural, burocrático, acadêmico, técnico, profissional, pequeno, grande, intermediário, democrático etc,não se estabelece a partir da atividade específica que essa categoria desenvolve, mas sim no sistema de relações sociais dentro do qual desempenha sua função.

Silva, ressalta que a perspectiva de mediadores na contemporaneidade tem sido apontada como nova explicação para a questão dos intelectuais e sua relação com as classes populares. Isto evidencia que mediadores "são sujeitos ou agentes cuja tarefa é destinada à realização de processos de mudança social, sejam àquelas de caráter comportamental ou as mudanças de visão de mundo de segmentos sociais diversos" (SILVA, 2007, p. 6).

Para a autora, a emergência do papel do mediador está intimamente ligada à morte do intelectual orgânico no contexto da crise da contemporaneidade - crise sistêmica, universal e estrutural da ordem capitalista iniciada em 1970 - cujos efeitos são sentidos na economia, no pensamento social, na academia, nas organizações políticas, na mídia, na produção intelectual e nas práticas políticas, fazendo com que os intelectuais reorganizem seus discursos e suas práticas.

Por sua perspectiva:

A crise traz consigo uma disputa de idéias, de visões de mundo e cria um ambiente político crítico que tem atingido direta e especialmente os intelectuais que ao longo da historia contribuíram para o fortalecimento da sociabilidade do trabalho, resultando seja no enfraquecimento da crítica teórica 
radical à ordem burguesa, seja no abandono da perspectiva de uma direção societária alternativa à mesma. A apreciação do fenômeno da crise atual e suas expressões apontam para a questão da disputa política por direção social e, sobretudo, para a possibilidade de conquista de hegemonia pelas classes subalternas na sociedade contemporânea, processo mediado pela ação dos intelectuais (SILVA, 2007, p. 4).

É importante destacar que as formas de organização da cultura que se compõe em processos de disputa por uma direção intelectual e moral não ocorrem de forma mecânica ou imediata. A autora assinala que um momento elementar deste processo é a assimilação, o quanto possível, de sujeitos que ocupam funções estratégicas no âmbito da educação e da cultura, ou ainda, a desagregação e enfraquecimento daqueles que até então conseguiam sustentar o bloco existente. Para ela é necessário salientar a existência, em meio à crise atual, de um movimento ofensivo do capital de assimilação dos intelectuais, de modo que no cenário de acirramento da disputa pela direção moral e intelectual na sociedade, alguns intelectuais que fortaleceram a sociabilidade do trabalho, foram frontalmente afetados, sendo assimilados para fortalecer o bloco de poder, dada sua função estratégica de organizador (SILVA, 2007).

Assim, neste cenário de crise orgânica, verifica-se a emersão de "novas" referências para o entendimento acerca dos intelectuais orgânicos, dentre as quais o surgimento de um "novo" sujeito representado pela figura do mediador cuja concepção atual é, de acordo com Silva (2007) insuficiente para revelar a posição, a formação e a função que os intelectuais desempenham na sociedade, já que não se localiza a posição (de classe) nem dos "mediadores" nem dos segmentos "mediados". Em relação a isto questiona:

Quem são estes sujeitos no jogo das relações sociais? Que projetos fortalecem? Quais concepções de mundo que partilham e difundem? Qual o contexto histórico e político no qual se opera sua intervenção? (SILVA, 2007, p. 7).

Assim, por sua ótica, a noção de mediador encontra-se saturada de determinações de ordem cultural e desprovida de outras determinações: nela esfacela-se a dimensão das relações de produção e das classes e enfatiza-se a dimensão da cultura, da política e das relações intersubjetivas, despolitizando a função dirigente do intelectual. Isto concede ao intelectual um posicionamento acima das classes, desenvolvendo uma intervenção "neutra" ou flutuante, e descomprometida em relação aos projetos presentes na sociedade.

O pensamento de Gramsci sobre os conceitos de hegemonia, contrahegemonia e intelectual orgânico, neste sentido, fornece um importante referencial para se pensar a uma "mediação" do ponto de vista conceitual, 
uma vez que incide luz sobre os conflitos e as dinâmicas de criação dos consensos que geram o distanciamento entre o público e as bibliotecas.

Assim, um projeto para uma biblioteca "verdadeiramente pública" precisa ter em vista a mediação como uma categoria que coloca em relevo as contradições que acabam por conformar o distanciamento entre 0 público e seus serviços.

Tal postura ancora-se, sobretudo, no questionamento, e mesmo no abandono, de algumas visões arraigadas no senso comum, tal como a própria ideia de mediação e leitura, que têm subsidiado a construção de discursos e de práticas que acabam por reificar o, muitas vezes, anódino lugar social ocupado pelas bibliotecas públicas.

Desse modo, pensar a mediação na esfera das bibliotecas pública implica em uma reflexão sobre os seguintes elementos apresentados a seguir.

1- Problematização do papel da biblioteca. A mediação que se quer realizar em uma biblioteca pública deve partir de uma crítica que incida luz para a constituição e, especialmente, para a função deste equipamento. Como lugares privilegiados de acesso à cultura escrita, cuja posse, em uma sociedade de classes, está historicamente distribuída de modo desigual, as bibliotecas públicas desempenham um papel social crucial, na medida em que garantem à população não apenas a resolução de um problema ou a resposta à uma demanda, mas antes, o exercício de um direito: o de acesso à produção cultural e simbólica acumulada pela humanidade. É preciso considerar os vínculos estabelecidos entre as formas de poder, a leitura e a escrita, compreendendo que o acesso a elas implica em uma intervenção na própria dinâmica das lutas sociais que engendram a realidade. Vislumbrando as tensões e contradições que historicamente regulam as práticas sociais de ler e escrever, é possível refletir sobre o que representa a inserção das pessoas no mundo da palavra escrita, reafirmando o papel da biblioteca para o acesso ao conhecimento socialmente construído.

2 - Ruptura com o senso comum que escamoteia as desigualdades e as relações de poder, naturalizando as dinâmicas das relações sociais. A mediação, neste sentido, nega a ideia harmoniosa de ponte para assumir o conflito. Este exercício nos leva a pensar criticamente sobre as questões que acabam por conformar o distanciamento entre o publico e a biblioteca, considerando que as barreiras são, prioritariamente, de ordem simbólica e material, historicamente constituídas. A ruptura com o senso comum coloca em xeque, de acordo com Brito (2009), mitos que se tornam verdades inquestionáveis, tais como a individualidade do gosto dos leitores, a interpretação livre e exclusiva de cada um deles, a leitura como ato redentor e como fonte 
inesgotável de prazer, a noção de atendimento à demanda, dentre tantos outros que se pautam pela lógica da normatividade produtiva e acabam por forjar um caráter idealizado para a leitura. O desvelamento dos consensos parte da compreensão de que as práticas sociais, dentre elas a leitura, se constroem no escopo de processos históricos e sociais, trazendo impressas as marcas dos antagonismos, lutas, contradições e relações de poder.

3 - Biblioteca como espaço de resistência: resistência ao pragmatismo que condiciona a vida à esfera do cotidiano, às produções massivas que privilegiam o entretenimento, que conforta e aliena, em detrimento da arte, que incomoda, propõe e questiona; resistência ao esquecimento que toma o lugar da memória e da agitação- tão estimulada pelas ações de "animação", em detrimento do silêncio que estimula a introspecção e a reflexão.

Se a hegemonia, segundo Gramsci ${ }^{11}$, se sustenta, dentre outros fatores, por meio de sentidos particulares que se metamorfoseiam de universais, é importante que a mediação em uma biblioteca proporcione meios para que aconteça o encontro e o confronto entre os diferentes códigos e universos simbólicos, abrindo possibilidades outras e autônomas de produção de sentidos. Recusar os imperativos do mercado, que contribuem para consolidação consciências alienadas, é uma ação política que deve estar refletida na escolha de acervos e atividades.

4 - Do imediato para o mediato. Mediar é procurar ultrapassar os limites do pensamento imediato para o mediato, intentando sair da percepção cristalizada de mundo no cotidiano e difundida pelos sistemas ideológicos para uma visão crítica da realidade, que tenha em vista a indagação sobre os consensos e a elaboração do pensamento autônomo. Neste sentido, a arte, especialmente, a literatura, é uma experiência profícua para um deslocamento simbólico que permite o questionamento da vida, da condição humana, a apreensão do real em suas tensões e contradições, na medida em que proporciona o encontro com o outro e convoca o desejo de pensar e construir diversos mundos, permitindo a saída do factual, das estruturas do cotidiano para questões mais profundas do ser humano.

5 - Entender a mediação como uma ação política. Com vista no mediato, a mediação deve ser uma ação orientada para emancipação dos sujeitos e para sua participação na

\footnotetext{
${ }^{11}$ Para Gramsci determinados blocos de poder organizam conhecimentos, consensos, significados e sentidos de modo que estes pareçam universais, fazendo com que a classe dominada conceba como "naturais" os interesses da classe dominante.
} 
intervenção da realidade, a partir do conhecimento. Como ação política ela deve negar, portanto, os mecanismos que engendram as consciências coisificadas, alienadas, buscando permitir a participação consciente do individuo nas práticas e processos sociais.

6 - Ter em vista a dialética entre o singular e o coletivo. Compreender, conforme propõe Lamizet (1998), que a mediação8 representa o imperativo social essencial da dialética entre o singular e o coletivo, e da sua representação em formas simbólicas. Para ele, a sociedade pode existir apenas se cada um dos seus membros tiver consciência de uma relação dialética necessária entre a sua própria existência e a existência da comunidade: "é o sentido da mediação que constitui as formas culturais de pertença e de sociabilidade dando-Ihes uma linguagem e dando-lhes as formas e os usos pelos quais os atores da sociabilidade apropriam-se dos objetos constitutivos da cultura que funda simbolicamente as estruturas políticas e institucionais do contrato social" (LAMIZET, 1998, p. 9). Neste sentido, a mediação não pode se contentar em forjar relações efêmeras, requerendo um acompanhamento que considere a permanente articulação e tensão entre o individual e o coletivo.

\section{7 - 0 bibliotecário, um intelectual.}

Um dos pontos chaves para a construção e consecução de projetos contra hegemônicos para as bibliotecas públicas é o retorno do bibliotecário para o seu papel de intelectual, aquele que "levanta publicamente questões embaraçosas, confronta ortodoxias e dogmas e representa pessoas e problemas que são varridos sistematicamente para debaixo do tapete" (SAID, 2005). Assumir o papel de intelectual em sua dimensão orgânica, como propõe Gramsci, é negar a função de mediador como articulador de consensos para assumir um papel de vetor da transformação social.

\section{Conclusões}

A nossa compreensão de mediação no âmbito das bibliotecas públicas, que confere destaque ao conflito e abandona a noção de ponte, busca ultrapassar a premissa reificante de que o acesso à leitura e à informação, necessariamente, esclarece dúvidas, reduz incertezas e gera um indivíduo apto para participar no mundo.

Isto porque as práticas sociais, dentre elas a leitura, a escrita e o uso das bibliotecas, trazem as marcas das delimitações histórico-culturais específicas e das lutas e antagonismos de diferentes naturezas que alocam os sujeitos e grupos sociais em posições desiguais no espaço 
social, o que acaba por conformar o distanciamento entre eles e as diferentes formas de produção simbólica.

Pensar a mediação pela perspectiva dialética implica considerar que as configurações entre mediação, informação e leitura não gozam de neutralidade na medida em que a dinâmica social é perpassada continuamente por contradições que a engendram, sendo necessário o desvelamento e enfrentamento das relações de poder inerentes a ela a partir da construção de projetos que visem sua transformação.

\section{Referências}

ALMEIDA, José Luiz Vieira de; ARNONI, Maria Eliza Brefere; OLIVEIRA, Edilson Moreira de. Mediação pedagógica: dos limites da lógica formal à necessidade da lógica dialética no processo ensino-aprendizagem. In: REUNIÃO ANUAL DA ANPED, 29., Caxambu, 2006. Anais... Caxambu: Associação Nacional de Pós-Graduação e Pesquisa em Educação, 2006. $15 p$.

em: <http://www.anped.org.br/reunioes/29ra/trabalhos/trabalho/GT04-1724Int.pdf $>$. Acesso em: 18 set. 2013.

ALMEIDA, Marco Antônio de. Mediação cultural e da informação: considerações socioculturais e políticas em torno de um conceito. In: ENANCIB, 8., 2007, Salvador, BA. Anais... Promovendo a inserção internacional da pesquisa brasileira em Ciência da Informação. Salvador, BA: Universidade Federal da Bahia, 2007. p. 1-6.

ALMEIDA, Marco Antônio. Mediações da cultura e da informação: perspectivas sociais, políticas e epistemológicas. Tendências da Pesquisa Brasileira em Ciência da Informação, v. 1, n. 1, p. 1-24, 2008.

ALVES, Maria Bernardete Martins; FAQUETI, Marouva Faullgatter. Mudanças no serviço de referência, em bibliotecas universitárias, sob o impacto das novas tecnologias. In: SNBU, 3., 2002, Recife, PE. Anais... Seminário Nacional de Bibliotecas Universitárias. Recife: UFPE, 2002.

ARISTÓTELES. Ética a Nicômaco. Bauru: Edipro, 2002. 287p.

BOURDIEU Pierre; CHAMBOREDON Jean-Claude; PASSERON Jean- Claude. A profissão de sociólogo: preliminares epistemológicas. Petrópolis: Vozes, 1999. 328p.

BRAGA, William Dias. Mediação e processos de compreensão intersubjetiva das representações sociais do trabalho. Datagramazero Revista de Ciência da Informação, v. 5, n. 3, p.1-15, jun. 2004. Disponível em: <http://www.dgz.org.br/fev09/F_I_aut.htm>. Acesso em: 5 dez. 2013.

BRITO, Luiz Percival de Leme. Leitura e participação. In: BRITO, Luiz Percival de Leme. Contra o consenso: cultura escrita, educação e participação. Campinas: Mercado das Letras, 2003. 
BRITO, Tiago. Marx e Lukács: a relação sociedade e natureza. In: COLÓQUIO MARX E ENGELS 6, 2009, Campinas, SP. Anais... Campinas: Unicamp, 2009. p. 1-9.

CAUNE, Jean. La médiation culturelle: une construction du lien social. Revue Lesnjeux de la Communications. 2000. 10p. Disponível em: <http://w3.ugrenoble3.fr/les_enjeux/2000/Caune/Caune.pdf>. Acesso em: 18 jan. 2009.

CONSELHO NACIONAL DE PESQUISA, 2013. Disponível em: <http://www.cnpq.br/>. Acesso em: 16 fev. 2013.

DAVALLON, Jean. A mediação: a comunicação em processo? Prisma, n. 4, p. 3-36, jun. 2007. Disponível em: <http://prisma.cetac.up.pt/A_mediacao_a_comunicacao_em_processo.pd f>. Acesso em: 14 dez. 2013.

FLUSSER, Victor. Uma biblioteca verdadeiramente pública. Revista da Escola de Biblioteconomia, Belo Horizonte, v. 9, n. 2, p. 131-138, set. 1980.

GAMEZ TORRES, Nora. El paradigma de la mediación: crítica y perspectivas. Mediaciones Sociales, v. 1, n. 1, 2007. Disponível em: <http://www.ucm.es/info/mediars/MediacioneS1/Indice/GamezTorres/ga meztorres.html>. Acesso em 23 de março de 2013.

GRAMSCI, Antonio. Cadernos do cárcere. Rio de Janeiro: Civilização Brasileira, 2007. v. 3.

GUARADY, Roger. Para conhecer o pensamento de Hegel. Porto Alegre: L \& PM, 1983.

HEGEL, Georg Wilhelm Friedrich. A razão na história: uma introdução geral à filosofia da história. São Paulo: Centauro, 2008.

JAPIASSÚ, Hilton; MARCONDES, Danilo. Dicionário básico de filosofia. 3. ed. rev. e ampl. Rio de Janeiro: Jorge Zahar Editor, 1976.

KONDER, Leandro. O que é dialética. 14. ed. São Paulo: Brasiliense, 1981. (Primeiros Passos, 23).

KOSIK, Karel. Dialética do concreto. Rio de Janeiro: Paz e Terra. 1976. $230 p$.

LALANDE, André. Vocabulário técnico e crítico da filosofia. São Paulo: Martins Fontes, 1993.

LAMIZET, Bernard. La médiation culturelle. Paris: L'Harmattan, 1998.

MARTINS, Ana Amélia Lage. Mediação: reflexões no campo da Ciência da Informação. 2010. 255f. Dissertação (Mestrado em Ciência da Informação)-Escola de Ciência da Informação, Universidade Federal de Minas Gerais, Belo Horizonte. 2010.

MARTINS, Ana Amélia Lage; REIS, Alcenir Soares. Sobre a migração de conceitos: uma discussão necessária. Datagramazero - Revista de Ciência 
da Informação, v. 15, n. 1, fev. 2014. Disponível em: <http://www.dgz.org.br/abr14/F_I_art.htm>. Acesso em: 26 fev. 2013.

MENEZES, Diego Sabado; HOBUSS, João. A doutrina aristotélica da medieidade. Disponível em: <http://www2.ufpel.edu.br/cic/2009/cd/pdf/CH/CH_00293.pdf>. Acesso em: 30 jan. 2013.

PUGLIESI, Márcio; BINI, Edson. Pequeno diccionario de filosofia. São Paulo: Hemus, 1997. p. 252-253.

RIBEIRO, Leila Beatriz; MARTELETO, Regina. Conhecimento e novas práticas informacionais nas ações político-pedagógicas de organizações não governamentais (ONG's). In: ENANCIB, 3., 1997, Rio de Janeiro, RJ. Anais... Rio de Janeiro, RJ: IBICT, 1997. 54-55.

RUSS, Jacqueline. Dicionário de filosofia. São Paulo: Scipione, 1994. p. 180 .

SAID, Edward. Representações do intelectual: as conferências de Reith. São Paulo: Companhia das Letras, 2005. 127 p.

SEMERARO, Giovanni. Gramsci e a sociedade civil: cultura e educação para a democracia. Petrópolis: Vozes, 1999. 279p.

SILVA, Eliane Andrade da. Os intelectuais diante da crise contemporânea. In: CONGRESSO BRASILEIRO DE SOCIOLOGIA, 12., 2007, Recife, PE. Anais... Recife, PE: Universidade Federal de Pernambuco (UFPE), 2007. Disponível em: <http://www.sbsociologia.com.br/congresso_v02/papers/GT8\%20Emanci pa\%C3\%A7\%C3\%A3\%20Cidadania\%20e\%20Reconhecimento/OS\%20INT ELECTUAIS\%20DIANTE\%20DA\%20CRISE\%20CONTEMPOR\%C3\%82NEA.p df>. Acesso em: 16 fev. 2013.

WILLIAMS, Raymond. Keywords: a vocabulary of culture and society. New York: Oxford University Press, 1985. p. 204-207. 